\title{
European market developments in prebiotic- and probiotic-containing foodstuffs
}

\author{
John Young \\ Director of Information, Leatherhead Food RA, Leatherhead, Surrey KT22 7RY, UK
}

\begin{abstract}
A growing number of food manufacturers in western Europe are beginning to explore the commercial opportunities for foodstuffs containing health-promoting microbial food supplements (probiotics) and health-promoting non-digestible food ingredients (prebiotics). A prebiotic is considered to affect the host beneficially by selectively stimulating the growth and/or activity of one or a limited number of naturally present or introduced bacterial species in the colon, also leading to a claimed improvement in host health. Increasingly, probiotics and prebiotics are used in combination, this being termed a synbiotic (Gibson \& Roberfroid, 1995). Throughout European history, fermented milk products in particular have been considered beneficial to health, but only in recent years has there been scientific support for these beliefs. Issues considered important to the continuing development of this growing market are proof of safety, proof of efficacy, consumer education, market positioning, price and appropriate health claims strategies. Until recently, much of the innovation in the use of probiotics and prebiotics has been in the dairy cabinet, with an ever-growing number and range of 'health-promoting' yoghurts and yoghurt-type fermented milk being made available to the European consumer, a market which is currently estimated to be worth in excess of \$US2 billion per annum (Hilliam et al. 1997). However, prebiotics are beginning to find increasing application outside the dairy sector, particularly in baked goods. A key driver behind the broadening application of prebiotics has been the pro-active stance taken by key prebiotic suppliers such as Beghin-Say, Orafti and Cosucra. To date, market activity in probiotic- and prebiotic-containing foods has centred around three health propositions, namely improving general gut health, lowering blood cholesterol and improving the body's natural defences.
\end{abstract}

Prebiotic: Probiotic: Functional foods

\section{Improving gut health}

Central to the development and introduction of products claiming to improve gut health and thereby general wellbeing has been the growing application of probiotics and prebiotics, both individually and in combination. Whereas the early products to market contained just a probiotic, manufacturers are increasingly exploiting the synergistic effect of combining a probiotic with a prebiotic. Examples of recent products claiming/implying that they improve gut health and thereby general well-being are:

(1) Symbalance: manufactured by the Swiss company Tonilait. This yoghurt contains the probiotic strains Lactobacillus reuterii, $L$. acidophilus and $L$. casei and the branded prebiotic RAFTILINE from Orafti, an inulin powder extracted from chicory roots, which is a mixture of poly- and oligosaccharides.

(2) Jour apres Jour: this is a UHT skimmed milk enriched in vitamins, trace elements and the branded prebiotic ACTILIGHT from the French company Beghin-Say. Manufactured by the French dairy company Lactel, the product is aimed at women wishing to maintain or improve their health status through daily consumption.
(3) Yakult: having established a European production base in The Netherlands in 1994, the Japanese company Yakult Honsha extended distribution of its fermented drink Yakult into Belgium, Luxembourg, the UK and Germany during 1995 and 1996. Developed in Japan more than 50 years ago, the citrus-flavoured beverage contains the probiotic $L$. casei. The basic health benefit posed is that regular (i.e. daily) consumption of Yakult leads to a healthier intestine and therefore a healthier body.

(4) PROBIOTIC plus Oligofructose: manufactured by the German company Bauer, this yoghurt contains the probiotic strains $L$. acidophilus and $L$. bifidus type LA7, and the prebiotic RAFTILOSE (oligofructose) from the Belgian company Orafti.

Other recent launches of interest are given in Table 1 .

\section{Lowering blood cholesterol}

The last couple of years has witnessed growing activity in products claiming to lower blood cholesterol, thereby contributing to a healthier heart. For example, Danone 
Table 1. Additional prebiotic- and probiotic-containing foodstuffs launched in Europe that claim to improve gut health

\begin{tabular}{lll}
\hline Product & Company & 'Acitve ingredient(s)' \\
\hline Actiline spread & Vamdermoortele (Belgium) & Inulin (poly- and oligosaccharides) \\
$\begin{array}{l}\text { Ligne Bifide dietetic range } \\
\text { (biscuits, ready meals, etc.) }\end{array}$ & Vivis (France) & Fructo-oligosaccharide \\
Low-sugar sorbet & Thiriet (France) & Fructo-oligosaccharide \\
Actimel Orange milk drink & Danone (Europe) & L. casei \\
ProCult 3 milk drink & Muller (Germany) & B. longum BB536 \\
Fyos Prebiotics fermented milk drink & Nutricia (Belgium) & \\
Acidophilus Tykmaelk fermented milk & Klover (Denmark) & L. acidophilus \\
Gefilus whey drink & Valio (Finland) & Lactobacillus GG \\
Yosa oat-based dessert & Bioferme Oy (Finland) & L. acidophilus, B. bifidium \\
Bifilus fermented milk & Arla (Sweden) & $\begin{array}{l}\text { Bifidobacterium longum, L. } \\
\text { bulgaricus, Streptococcus } \\
\text { thermophilus }\end{array}$ \\
ProViva rosehip drink & & \begin{tabular}{l} 
L. plantarum 299v \\
\hline
\end{tabular}
\end{tabular}

launched Actimel Cholesterol Control yoghurt in Belgium, containing the cholesterol-lowering probiotic $L$. acidophilus and the branded prebiotic ACTILIGHT (Beghin-Say), while the Dutch company Mona introduced a cultured dairy-based drink under the Fysiq brand. Fysiq contains the probiotic $L$. acidophilus Gilliland and the branded bifidogenic fibre, RAFTILINE (Orafti).

Another key player in this area is the Danish company MD Foods with its cultured yoghurt-style product Gaio. Introduced in Denmark in 1993, the product was very successful, capturing $15 \%$ of the Danish yoghurt market in just 1 year. However, the product was not successful in the UK being withdrawn due to unsatisfactory sales levels coupled with adverse media coverage surrounding its cholesterol-lowering claims. The active principle of Gaio is a probiotic referred to as Causido culture.

The strident cholesterol-lowering claims for Gaio from MD Foods led to significant negative public relations in the UK, driven not only by competitor companies but by a number of consumer pressure groups, notably the National Food Alliance and the London Food Commission. Gaio's problems were compounded when the UK's Advertising Standards Authority ruled that MD Foods claims for Gaio were excessive, thereby forcing them to amend all advertising.

\section{Improving the body's natural defences}

The European market has also witnessed significant activity in products claiming to strengthen the body's immune system or its natural defences. The most successful product on the market is $\mathrm{LCl}$ from the major multinational food company, Nestlé. LC1 was the outcome of a research project launched at the Nestlé R \& D centre in Lausanne in 1989, the aim of which was to identify health-promoting strains of bacteria within its collection of bacterial strains used in the manufacture of fermented, speciality milk products. While the product has been very successful in France, Germany, Switzerland and Italy, a slower start has been evident in a number of other countries, notably the UK. The reason for this is that the UK consumer is still comparatively poorly educated on yoghurt characteristics and live cultures. Indicative of the success of $\mathrm{LCl}$ is that it has added considerable volume to Nestlé's European yoghurt activities and now accounts for approximately $20 \%$ of their yoghurt business.

\section{Conclusion}

It is clear that the European market is witnessing considerable activity in the application of prebiotics and probiotics in foodstuffs, with the main applications to date in the dairy sector. However, as already indicated, a health claim is no guarantee for success, the UK withdrawal of Gaio being a case in point. Nevertheless, despite the inevitable winners and losers, the market for such products is estimated to be showing double-digit annual volume growth and is forecast to continue to do so for the foreseeable future. Seen as important to the continued growth of the market will be the growing requirement to prove efficacy and educate the consumer on the various health propositions accompanying these products. In common with all other foodstuffs, success will also depend on correct market and price positioning and in the case of these and other health-promoting foodstuffs, meaningful health claims terminology (Young, 1996).

Seen as critical to the future growth of the market are practices that engender confidence in these, and indeed other health-promoting foodstuffs, among consumers, law enforcers and indeed the industry itself. To this end, a number of national authorities have, or are in the process of, establishing codes of practice as a means to achieving this objective. Countries having taken such an initiative include the UK, Sweden, Holland and Belgium. For example, the UK is shortly to issue a code of practice 
resulting from the Joint Health Claims Initiative by the Food and Drink Federation, the National Food Alliance and LACOTS, the local authorities coordinating body on food and trading standards. It is hoped that the Code will bring a measure of self-regulation to the industry, particularly in the areas of health claim substantiation and consumer information.

The need to prove safety as well as efficacy is also of paramount importance and to this end it is recommended that an integral element of a company's strategy should be a comprehensive scientific dossier covering both health and nutritional safety. Some of the key areas for the substantiation of nutritional safety are intake, extent of use, presence of antinutritional factors, implications for potential changes in gut microflora, impact on metabolic pathways, overall toxicological assessments, history of safe use and potential effects on vulnerable groups, e.g. the young, pregnant women and the elderly.

For prebiotic- and probiotic-containing foodstuffs to realize their full potential the consumer will need to be educated about their various health propositions and how they should be used within the context of a normal dietary pattern. In this respect government can play an important role by creating an environment that lends credence to the role of certain dietary constituents in disease prevention.

If these issues are addressed it is not inconceivable that the European demand for prebiotic- and probiotic-containing products will continue to register strong growth for the foreseeable future, climbing to around \$US3 billion by the year 2000 .

\section{References}

Gibson GR \& Roberfroid MB (1995) Dietary modulation of the human colonic microbiota: introducing the concept of prebiotics. Journal of Nutrition 125, 1401-1412.

Hilliam MA, James A \& Young IN (1997) Leatherhead Food RA Multi-Client Study, The European Market for Functional Foods - Current Developments and Future Prospects. UK: Leatherhead Food Research Association.

Young J (1996) Financial Times Management Reports, Functional Foods - Strategies for Successful Product Development. UK: Leatherhead Food Research Association. 